\title{
Conflict induced fixation of stereotyped lever pressing responses'
}

HARBANS LAL

UNIVERSITY OF KANSAS, LAWRENCE, KANSAS

A conflictful situation was produced by a schedule in which a discriminated response which had previously been associated with the reward was not consistently rewarded or punished and pressure was applied to force a responsc. About 15 sessions of the insoluble problem after the acquisition of a soluble problem produced behavioral fixation.

Maier (1949) and Feldman (1957) reported that the rats subjected to a conflictful insoluble problem situation on Lashley's jumping apparatus developed irreversible stereotyped position preferred jumping responses. Since jumping as a response and a window as a stimulus limit the experimental variables which can be studied a procedure was developed to produce behavioral fixation using lever pressing in a Skinner box as a response. Feldman \& Green (1966) recently employed a similar procedure in squirrel monkeys.

Method

The apparatus consisted of a sound insulated behavioral box (LeHigh model 1316) equipped with two levers, one on each side with a cue light mounted on each of the levers. The levers and the cue lights could be manipulated independently. The responses were recorded on Gerbrand cumulative recorders.

Two $23 \mathrm{hr}$. water deprived Sprague-Dawley albino male rats were trained to press a lever when a cue light was presented. The cue was presented on either the right or the left lever after a variable interval of 30 sec. elapsed since the last response. During the soluble problem schedule, the water reinforcing lever and the cue light were always paired. A response on the lever with the cue energized the water dipper while a response on the other lever delivered a grid shock of $0.8 \mathrm{ma}$ intensity for $0.2 \mathrm{sec}$. If no response was emitted during the first $10 \mathrm{sec}$. after the cue presentation, a continuous buzzer was sounded and the grid was shocked every 2 sec. A response on either of the levers terminated both the buzzer and the oncoming shock.

Once the animal learned to press a correct lever irrespective of its position and this behavior was emitted reliably during several daily sessions, the insoluble schedule with a conflictful situation was initiated. During this schedule the cue was presented in an irregular order, that is, neither a particular cue nor a particular position of the lever was consistently correct or incorrect. Thus neither right nor left lever pressing rewarded or punished consistently. The animals initially showed a state of variability in their choices and soon thereafter refused to respond. This resistance to the response was overcome by the discontinuous grid shocks which followed after $12 \mathrm{sec}$. The later schedule was designated as the insoluble problem situation because there was a problem that could not be solved and because pressure was applied to force a response.

Two additional control rats were trained to acquire cue reward preference after they had learned the position reward responses. In the first phase they were trained on the continuous reinforcement schedule in

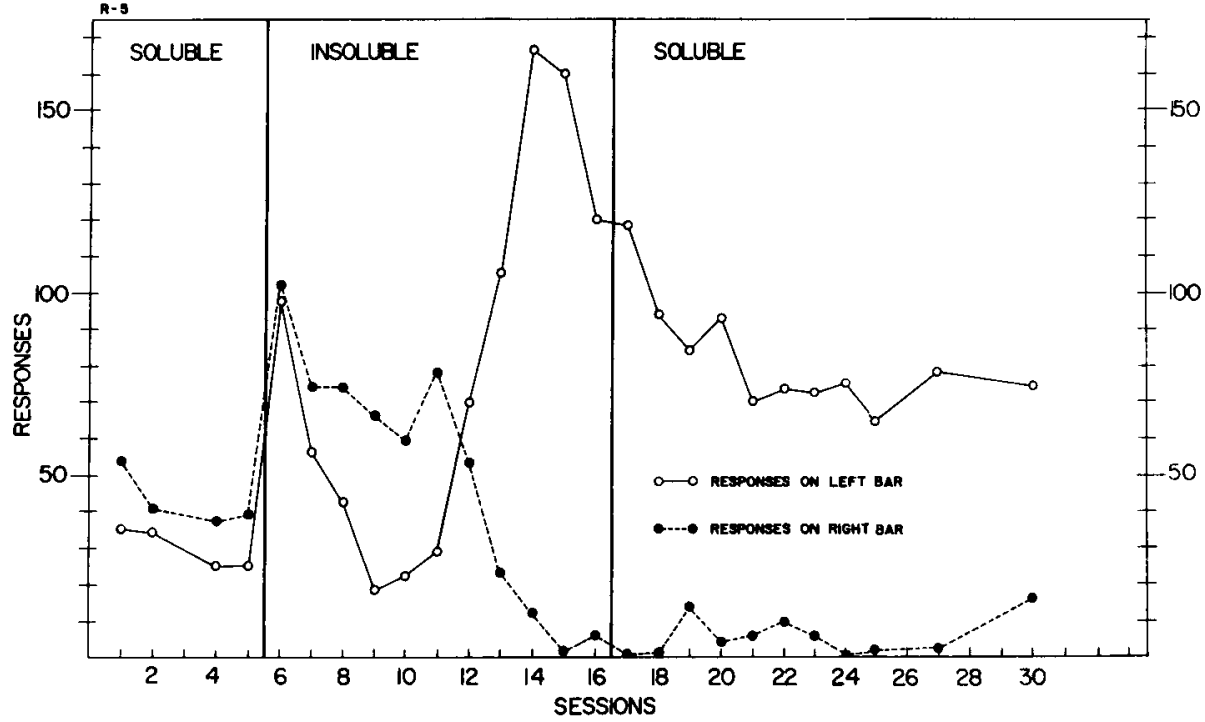

Fig. 1. Lever pressing responses of a typical fixated rat. 
which they were required to alternate the right and left levers after every 10 responses. In the second phase they were required to follow the cue light which alternated from one lever to the other after the variable interval of $16 \mathrm{sec}$.

\section{Results}

Total daily responses on the left and the right lever by one of the experimental rats are illustrated in Fig. 1. The other rat showed similar behavior. It is seen that after six daily sessions of the insoluble problem the rat chose to press left lever consistently. The responses on the left lever were emitted irrespective of the position of the cue light which alternated randomly after every response and despite the fact that they were punished half of the time. This behavior was irreversible in that the stereotyped responses persisted during subsequent soluble problem sessions. The adaptation during the insoluble problem was considered fixated (irreversible) only when the response stereotypy was practiced without variation during at least 10 sessions of the soluble problem following the last session of the insoluble problem schedule. The control rats trained to follow the position of the lever acquired their new preference of following the cue light within three sessions. Although these rats may have not constituted the proper controls because the experimental conditions were not identical they showed that an animal not confronted with a conflictful insoluble problem could learn to follow a new cue rather rapidly. In contrast, the fixated rats did not learn to solve the problem to their advantage. Discussion

The results of this experiment demonstrated that the behavioral fixation similar to the one reported by Maier can be achieved through operant conditioning using lever pressing as a response. This procedure offers several theoretical and practical advantages. It permits to vary the stimulus and reinforcement characteristics and therefore more precise analysis of the fixated behavior is possible. Whenever required, the frequency of the responses can be altered and measured as a dependent variable. Since the animal is always free to respond, the method interacts minimally with the behavior. The high environmental control in the Skinner box and automatic, direct and continuous recording of the emitted responses are easily achieved.

\section{References}

Feldman, R. S. The role of primary drive reduction in fixations. Psychol. Rev., 1957, 64, 85-90.

Feldman, R. S., \& Green, K. F. Effects of chlordiazepoxide on fixated behavior in squirrel monkeys. J. Psychopharmacol., $1966,1,37-45$

Maier, N. R. F. Frustration. McGraw-Hill, New York, 1949.

\section{Note}

1. Technical assistance of Mary Ann Robinson is appreciated. The investigation was supported by Grant GE-1128 from National Science Foundation. Reprints may be obtained from Harbans Lal, Associate Professor of Pharmacology and Toxicology, University of Kansas, Lawrence, Kansas 66044.

\section{Errata}

Smith, E. Effects of extreme heat stress on retention in the white rat. Psychon. Sci., 1966, 6 (3) 127-128.The 6 th line, left column, page 128 , should read "ture of $43.5^{\circ} \mathrm{C}$ at a chamber temperature of $50.0^{\circ} \mathrm{C}$, one half of the rats under 250 gm died."
Corson, J. A., \& Enesco, Hildegard E. Some effects of injections of ribonucleic acid. Psychon. Sci., 1966, 5 (5), 217-218. - The first reference to the use of RNA in the introduction should have been to Cameron, D. E., Amer. J. Psychiat., 1958, 114, 943, rather than to Camerson et al (1961). 